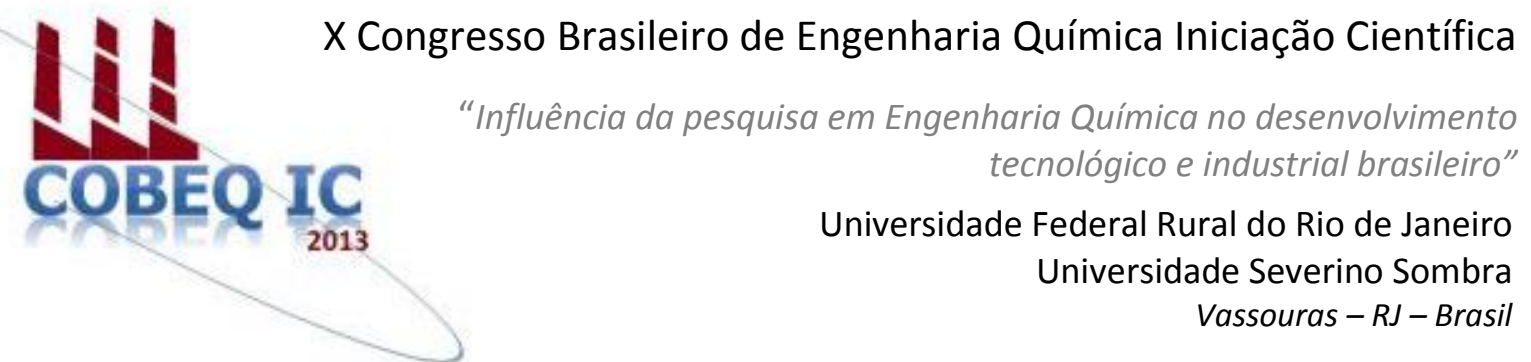

\title{
SECAGEM DA CASCA DO ABACATE (PERSEA AMERICANA) E A AVALIAÇÃO DO COMPORTAMENTO DO TEOR COMPOSTOS BIOATIVOS
}

\author{
CUNHA*1, P. M. C.; PEIXOTO $^{1}$, Y. P.; ULLMANN ${ }^{1}$, G.; SILVA ${ }^{2}$, D. I. S.; BARROZO³ ${ }^{3}$ M. \\ A. S. \\ ${ }^{1}$ Alunos da FEQ/UFU ${ }^{2}$ Doutorando da FEQ/UFU ${ }^{3}$ Professor da FEQ/UFU \\ Faculdade de Engenharia Química - Universidade Federal de Uberlândia \\ Endereço-UFU, Av. João Naves de Ávila, 2121, Bloco 1K, Campus Santa Mônica, Uberlândia - MG, \\ CEP 38408-100. \\ E-mail: masbarro@ufu.br
}

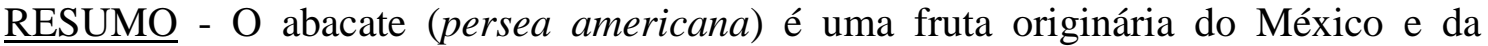
América Central, sendo que a riqueza em proteínas, lipídios, vitaminas, minerais como ferro, cálcio, fósforo e antioxidantes faz deste fruto um importante fator no combate a desnutrição. A casca também é fonte nutricional, como por exemplo, de fitonutrientes que combatem os radicais livres e flavonoides que são antioxidantes que retardam o envelhecimento celular. Mas esta recebe pouca atenção ao consumo, sendo muitas vezes descartada produzindo um lixo úmido que proporciona a atividade microbiana, degradando os nutrientes da mesma. A secagem de alimentos é um método que retira umidade dos produtos dificultando o desenvolvimento de microrganismos e a atividade enzimática, fazendo com que o material demore mais tempo para se decompor, além de proporcionar menos custos em armazenamento e transporte, uma vez que volume e peso são reduzidos. Assim, o objetivo desse trabalho foi estudar o comportamento dos compostos bioativos, como acidez, vitamina $\mathrm{C}$ e flavonóides, na casca do abacate in natura e após secagem sob luz de infravermelho. Foram avaliadas as temperaturas: 70 80 , e $90{ }^{\circ} \mathrm{C}$. Os resultados mostraram que a secagem por infravermelho é eficiente na conservação do teor dos compostos bioativos.
\end{abstract}

Palavras chave: infravermelho, antioxidantes, cinética.

\section{INTRODUÇÃO}

O abacate é um fruto rico em proteínas e vitaminas sendo uma ótima opção para a composição da alimentação diária. $\mathrm{O}$ consumo dele pode ajudar no emagrecimento, pois é rico em ômega 6, ômega 9 e ômega 7, que equilibram o organismo. Segundo a nutricionista Karin Honorato, o abacate possui também vitamina $\mathrm{E}$, que faz as gorduras terem ação anti-inflamatória (G1 MG, 2013).

$\mathrm{O}$ fruto é usualmente aplicado em rações animais, no consumo in natura ou em vitaminas. Assim também como na polpa, a casca do abacate contém fitonutrientes que inibem a atividade de radicais livres, fato que confere grande parte das características benéficas ao consumo desse fruto, além de ter 
ação vermífuga contra parasitas (MINISTÉRIO DA SAÚDE, 2002).

Uma grande produção acarreta a formação de resíduos. O crescimento desse material gera problemas aos municípios, seja devido à falta de espaços físicos para a deposição, seja pelos custos envolvidos para o gerenciamento dos resíduos urbanos (CARLI, 2010).

Assim, uma medida alternativa é o aproveitamento de cascas dessas frutas. Silva et al. (2009) propõem a fabricação de barras de cereais com o resíduo de maracujá, mas para o início desse processo faz-se necessário à secagem do material, a fim de retirar o máximo possível de umidade para impedir a atividade microbiana, que degrada a maioria de seus compostos bioativos.

Em geral, entende-se por secagem a operação unitária destinada à remoção de um líquido agregado a um sólido para uma fase gasosa insaturada através de vaporização térmica. A fase gasosa deve ser não saturada para que possa receber a umidade como vapor. $\mathrm{O}$ mecanismo de vaporização térmica para a remoção da umidade distingue a secagem dos processos de filtração e centrifugação (PACHECO, 2012).

Duzzioni et al. (2013) secaram resíduo de acerola em um secador de leito fixo de camada fina, mas segundo Marques (2008) secou abacaxi, acerola, goiaba, mamão papaia e manga a partir da liofilização (sublimação da água do sólido), mas segundo Marques e Freire (2005) a liofilização oferece, geralmente, produtos de superior qualidade, mas sua aplicação tem sido limitada pelos altos custos do processo. Isso nos leva a necessidade de outras formas de secagem, como a partir de luz infravermelha.

O processo de secagem de alimentos por infravermelho é um processo radioativo, ou seja, neste processo a energia é transportada na forma de ondas eletromagnéticas, com um comprimento de onda fixo. Os principais componentes alimentícios são capazes de interagir com esta faixa de comprimento de onda resultando em um fenômeno complexo que tem como consequência o aquecimento do alimento. Os sólidos a serem secos em geral absorvem a radiação em uma estreita camada na superfície. Esse tipo de secagem é mais comum para fatias de pão, chá, especiarias e amêndoas, por exemplo, (PUHL e NITZKE, 20013).

Um importante composto bioativo é o ácido ascórbico (vitamina $\mathrm{C}$ ), com habilidade de perder e captar hidrogênio, essencial no metabolismo. Essa vitamina está envolvida na síntese do colágeno, no desenvolvimento do tecido conjuntivo, no processo de cicatrização e recuperação após queimaduras e ferimentos (BASU, 2006).

Os compostos fenólicos são substâncias amplamente encontradas na natureza, sendo que mais de 8000 compostos fenólicos já foram detectados em plantas. Os flavonoides compreendem um grupo de compostos fenólicos amplamente distribuídos nas frutas e nos vegetais agindo como antioxidantes, não somente pela sua habilidade em doar hidrogênio ou elétrons, mas também em virtude de seus radicais intermediários estáveis, que impedem a oxidação de vários ingredientes do alimento, particularmente de lipídios. (BRAND-WILLIAMS et al., 1995).

Assim, o objetivo desse trabalho foi avaliar o comportamento dos compostos bioativos (, ácido ascórbico e flavonoides) e do ácido cítrico após a secagem da casca de abacate através de radiação infravermelha.

\section{MATERIAIS E MÉTODOS}

\section{Material}

As cascas de abacates utilizadas nos experimentos foram obtidas em um estabelecimento de hortifrúti próximo a Universidade Federal de Uberlândia, no campus Santa Mônica, na cidade de Uberlândia - MG.

\section{Condições de Secagem}

$\mathrm{O}$ estudo da secagem foi realizado em um aparelho medidor de umidade com o fornecimento de calor através de luz infravermelha, conforme a Figura 1.

As temperaturas avaliadas para a fonte de calor do equipamento foram 70,80 e $90{ }^{\circ} \mathrm{C}$.

Procedimento experimental: Pesou-se o material utilizado, e após ligar o aparelho, que foi previamente aquecido, no modo "medir umidade" o prato de alumínio descartável foi 
tarado, o sólido depositado e pesado pelo equipamento e a secagem iniciada.

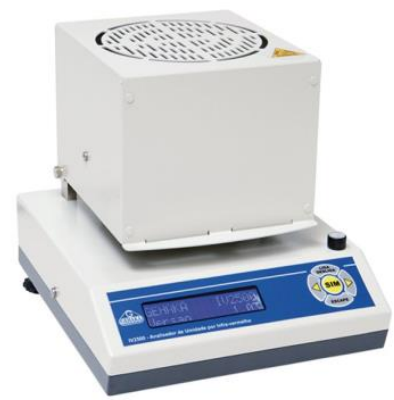

Figura 1 - Medidor de umidade utilizado para a secagem.

No visor do aparelho era informado o tempo e a porcentagem de material seco. A secagem se estendeu até que num intervalo de 1 minuto a porcentagem de material seco aumentasse menos que $0,1 \%$. Assim, o material foi retirado do equipamento, pesado e guardado em um vidro, lacrado e envolvido por papel alumínio e colocado em um dessecador.

A umidade de equilíbrio (equilíbrio dinâmico) utilizada para o cálculo do adimensional de umidade (MR) foi obtida no final de cada experimento. O cálculo do adimensional de umidade foi realizado conforme a Equação 1.

$$
M R=\frac{M-M e q}{M o-M e q}
$$

\section{Teor de Acidez Total Titulável e Ácido Ascórbico}

A acidez total titulável (expressada em $\%$ de ácido cítrico) das amostras foi realizada de acordo com os métodos da Association of Official Analytical Chemists. O conteúdo de ácido ascórbico, por sua vez, foi determinado por titulometria, método que se baseia na redução do 2,6-diclorofenol-indofenol pelo ácido ascórbico, e os resultados expressos em $\mathrm{mg}$ de ácido ascórbico em 100g de amostra (base seca) (AOAC, 1995).

\section{Teor de Flavonoides totais}

O conteúdo de flavonóides totais foi determinado pelo método colorimétrico segundo Zhishen et al., (1999). Preparou-se uma curva padrão com rutina em concentrações variando de 0,2 a $2,0 \mathrm{mg} \mathrm{mL}-1$, utilizando o metano como extrator. Os resultados foram expressos em mg equivalente de rutina em $100 \mathrm{~g}$ de amostra (base seca).

\section{Tratamento Estatístico}

$\mathrm{Na}$ seleção do melhor modelo para predizer a cinética de secagem foram considerados: a significância dos parâmetros dos modelos, a magnitude do coeficiente de correlação $\left(\mathrm{R}^{2}\right)$ e a distribuição dos resíduos que deve ser de forma independente $\mathrm{e}$ aleatória. Os modelos de cinética de secagem que foram ajustados aos dados experimentais são apresentados na Tabela 1.

Tabela 1 - Modelos de cinética de secagem

\begin{tabular}{cc}
\hline Equação & Referência \\
\hline$M R=e^{-k t}$ & Lewis (1921) \\
\hline$M R=A e^{-k t}$ & $\begin{array}{c}\text { Brooker } \text { et al. } \\
(1974)\end{array}$ \\
\hline$M R=A\left(e^{-k t}+\frac{1}{9} e^{-9 k t}\right)$ & Henderson \& \\
Henderson (1968) \\
\hline$M R=\exp \left(-k t^{n}\right)$ & Page (1949) \\
\hline$M R=\exp -(k t)^{n}$ & Overhults et al. \\
& $(1973)$ \\
\hline
\end{tabular}

Todas as análises dos compostos antioxidantes foram realizadas em triplicata e os resultados expressos em média \pm desvio padrão (SD).

\section{RESULTADOS E DISCUSSÕES}

\section{Cinética de Secagem}

Na discriminação estatística de modelos rivais (Tabela 1), considerando-se todos os aspectos estatísticos, o modelo cinético que apresentou melhores resultados foi o modelo Overthults.

$\mathrm{Na}$ Tabela 2 são apresentados os parâmetros de condições de operação do melhor modelo para o material estudado neste trabalho.

Tabela 2 - Parâmetros do modelo Overhults

\begin{tabular}{ccc}
\hline $\mathbf{T}$ & \multicolumn{2}{c}{$\begin{array}{c}\text { Parâmetros do modelo } \\
\text { Overhults }\end{array}$} \\
\cline { 2 - 3 }$\left({ }^{\mathbf{C}} \mathbf{C}\right)$ & $\mathrm{k}$ & $\mathrm{n}$ \\
\hline $\mathbf{7 0}$ & 0,000120 & 1,066707 \\
\hline $\mathbf{8 0}$ & 0,000170 & 1,166500 \\
\hline $\mathbf{9 0}$ & 0,000207 & 1,159910 \\
\hline $\mathbf{R}^{2}$ (média) & \multicolumn{2}{c}{0,9989} \\
\hline
\end{tabular}


Nas Figuras 2, 3 e 4 estão apresentados os dados experimentais e a previsão do modelo de Overhults para o adimensional de umidade (MR), como uma função do tempo de secagem (t). Através de uma análise destes valores observa-se que a equação Overhults descreve bem a cinética de secagem do resíduo de abacate e que a remoção de água durante a secagem deste material ocorre principalmente no período de taxa decrescente, conforme também observado para resíduo de acerola de Duzzioni et al. (2013) e resíduo de abacaxi por Silva et al. (2013).

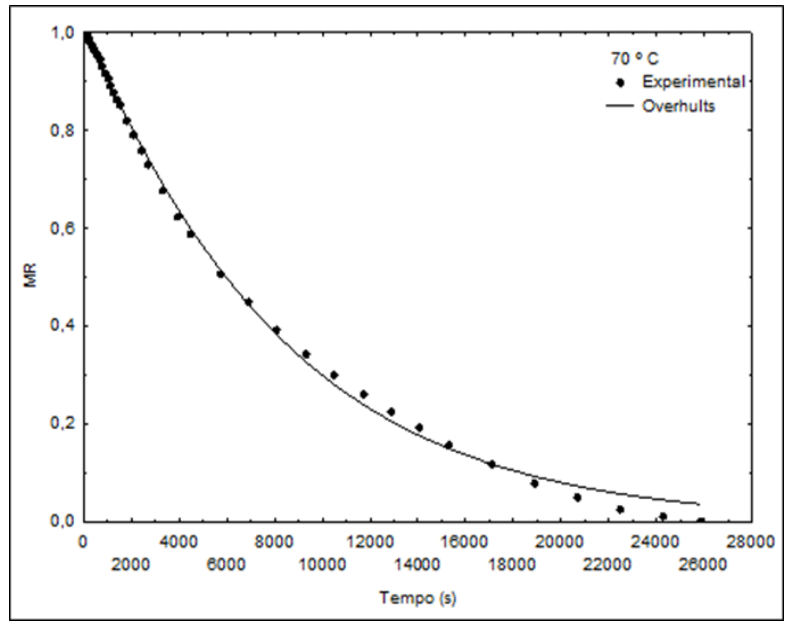

Figura 2 - Cinética de secagem á $70{ }^{\circ} \mathrm{C}$, dados experimentais e previstos por Overhults.

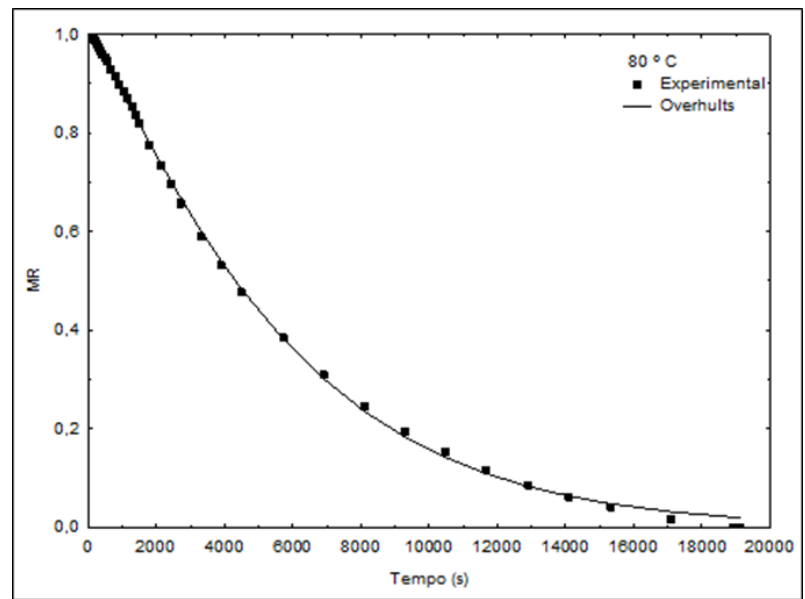

Figura 3 - Cinética de secagem á $80^{\circ} \mathrm{C}$, dados experimentais e previstos por Overhults.

Na Figura 5 estão apresentadas as curvas de dados experimentais nas três temperaturas. Nota-se que a $90{ }^{\circ} \mathrm{C}$ obteve menor tempo de secagem e a $70{ }^{\circ} \mathrm{C}$ o maior tempo.

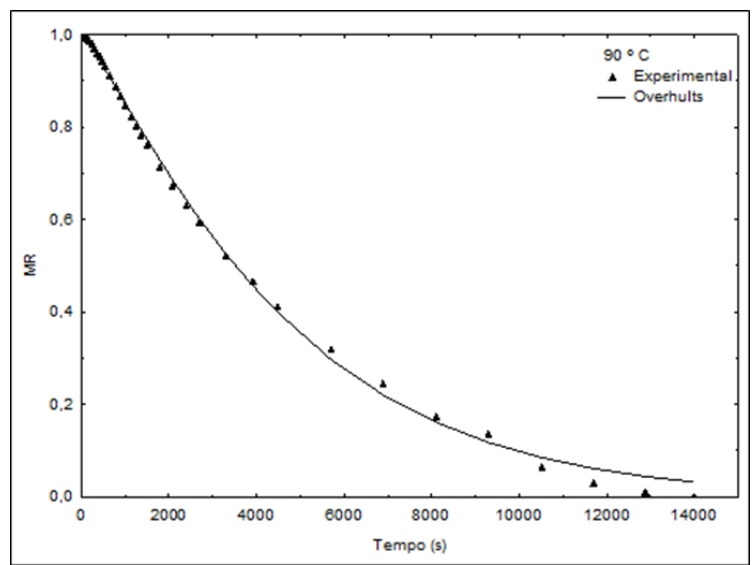

Figura 4 - Cinética de secagem á 90 ${ }^{\circ} \mathrm{C}$, dados experimentais e previstos por Overhults.

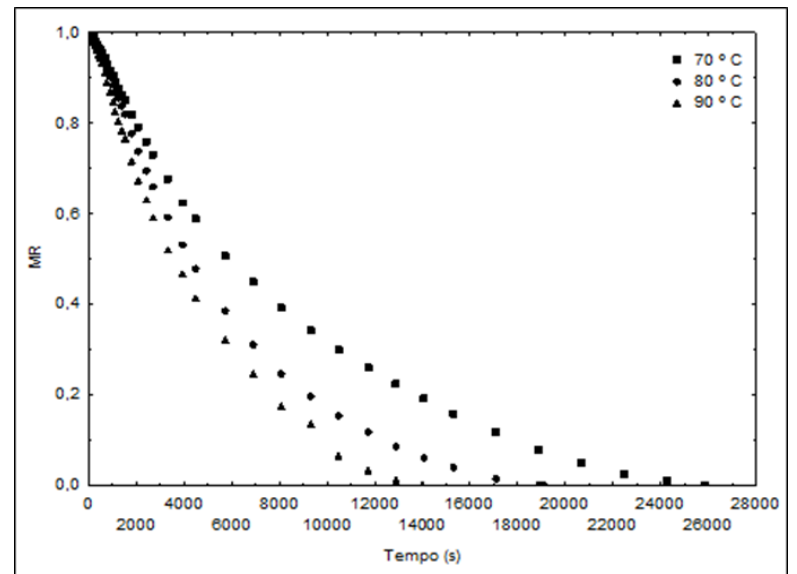

Figura 5 - Cinética de secagem á 70, 80 e 90 ${ }^{\circ} \mathrm{C}$, dados experimentais.

\section{Análises Físico-químicas}

A temperatura e as condições de secagem podem afetar a atividade e a estabilidade dos compostos bioativos pela degradação química e enzimática, por volatilização e decomposição térmica (DORTA et al., 2012). Assim, neste trabalho, foi avaliado o efeito da temperatura do ar de secagem no teor de acidez total, ácido ascórbico e flavonoides totais presentes na amostra após a secagem.

O teor de acidez total obtido nas diferentes amostras de casca de abacate foi de $1,37 \pm 0,19 \mathrm{~g}$ de ácido cítrico $100 \mathrm{~g}^{-1} \mathrm{de}$ amostra (base seca), enquanto que para as amostras secas os valores obtidos foram $0,90 \pm$ $0,09 \mathrm{~g}$ de ácido cítrico $100 \mathrm{~g}^{-1}$ amostra, 0,93 \pm $0,07 \mathrm{~g}$ de ácido cítrico $100 \mathrm{~g}^{-1}$ de amostra e $0,83 \pm 0,01 \mathrm{~g}$ de ácido cítrico $100 \mathrm{~g}^{-1} \mathrm{de}$ amostra (base seca), a 70, 80 e $90{ }^{\circ} \mathrm{C}$, respectivamente (Figura 6). 


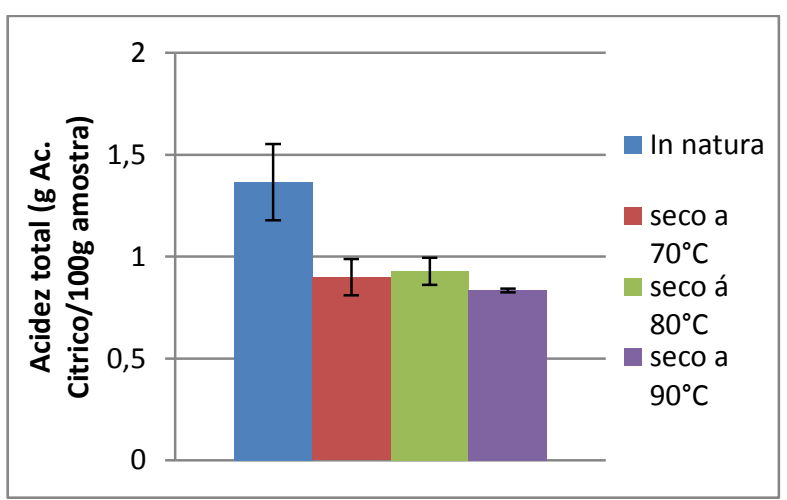

Figura 6 - Teor de acidez titulável contida na casca do abacate in natura e após secagem.

O teor de ácido ascórbico encontrado na casca in natura foi de $24,15 \pm 3,15 \mathrm{mg}$ de ácido ascórbico $100 \mathrm{~g}^{-1}$ de amostra. Após a secagem o menor valor obtido foi 12,12 $\pm 0,94$ $\mathrm{mg}$ de ácido ascórbico $100 \mathrm{~g}^{-1}$ de amostra, seco a $80{ }^{\circ} \mathrm{C}$. De acordo com o teste tukey realizado não houve diferença significativa com valor obtido para a temperatura de $90{ }^{\circ} \mathrm{C}$ $\left(13,64 \pm 1,10 \mathrm{mg}\right.$ de ácido ascórbico $100 \mathrm{~g}^{-1} \mathrm{de}$ amostra) e o seco a $70{ }^{\circ} \mathrm{C}$ obteve teor de 18,56 $\pm 1,72 \mathrm{mg}$ de ácido ascórbico $100 \mathrm{~g}^{-1} \mathrm{de}$ amostra (Figura 7).

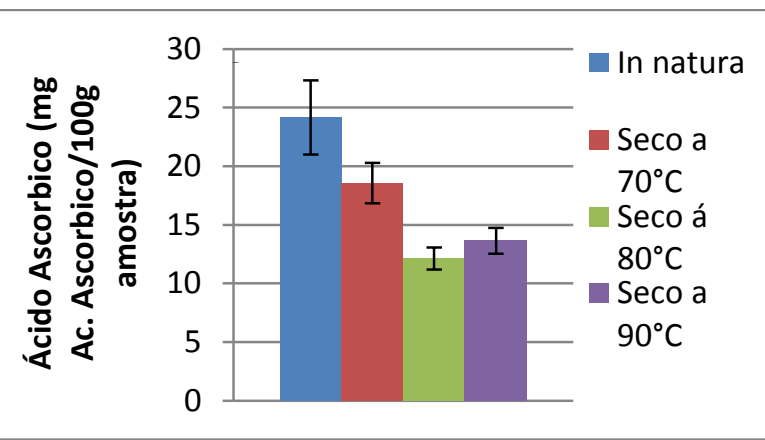

Figura 7 - Teor de Ácido Ascórbico contido na casca de abacate in natura e após secagem.

Em particular, a vitamina $\mathrm{C}$ (ácido ascórbico) é considerada ser um indicador de qualidade de alimentos processados, devido à sua baixa estabilidade durante os tratamentos térmicos (PODSEDEK, 2007). Assim, o método de secagem estudado neste trabalho pode ser considerado eficaz, pois a degradação do material não foi tão alta.

O teor de flavonoides totais da casca do abacate após secagem e fresco (polpa e casca) pode ser visto na Figura 8.

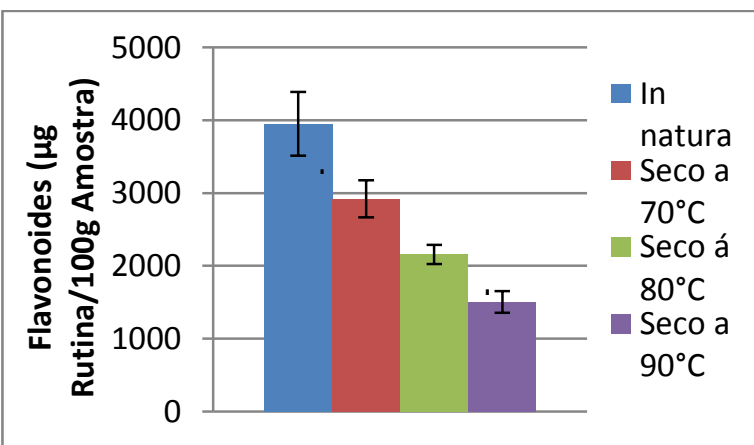

Figura 8 - Teor de Flavonoides da casca de abacate in natura e após secagem.

Observa-se o aumento da degradação com o aumento da temperatura de secagem, pois na amostra in natura o teor de flavonoides foi de $3951,49 \pm 438,23 \mu \mathrm{g}$ de rutina $100 \mathrm{~g}^{-1}$ de amostra, enquanto que a $70{ }^{\circ} \mathrm{C}$ foi de $2920,95 \pm 252,46 \mu \mathrm{g}$ de rutina $100 \mathrm{~g}^{-1} \mathrm{de}$ amostra e $2158,09 \pm 130,95$ e $1502,39 \pm$ $149,60 \mu \mathrm{g}$ de rutina $100 \mathrm{~g}^{-1}$ de amostra para as temperaturas de 80 e $90{ }^{\circ} \mathrm{C}$, respectivamente.

\section{CONCLUSÃO}

A cinética de secagem da casca de abacate por infravermelho foi eficiente nas condições estudadas neste trabalho. Apesar de não ter sido encontrado outros trabalhos na literatura que trata da secagem da casca dessa fruta, observou-se que o comportamento foi semelhante a outros estudos de secagem usando frutas semelhantes. A discriminação estatística de modelos rivais demonstrou que o modelo de Overhults (Overhults et al., 1973) foi o de melhor representação dos dados experimentais da casca do abacate.

Quanto ao teor de compostos bioativos analisados neste trabalho, nota-se que os valores para a casca in natura são significativos, ou seja, não se pode descarta-la considerando que esta é uma fonte para complementar a alimentação humana por prevenir doenças. A secagem também se mostrou eficiente.

Enfim, os resultados apresentados neste trabalho indicam que o processo de secagem pode manter um valor nutricional, da casca de abacate, aceitável para a dieta humana. Assim, uma vez tratado corretamente, a casca perdida pela utilização da fruta pode ser reutilizada para diversos propósitos, considerando-a como uma fonte de compostos bioativos, evitando 
assim a descarga para o meio ambiente. Assim, novos produtos podem ser gerados com um maior valor nutricional.

\section{NOMENCLATURA}

A - Parâmetro dos modelos de cinética de secagem, adimensional

k - Parâmetro dos modelos de cinética de secagem, com unidade de tempo ${ }^{-1}$

M - Massa do conjunto prato e amostra

Meq - Massa do prato

Mo - Massa do conjunto prato e amostra, inicialmente.

MR - adimensional de umidade

\section{REFERÊNCIAS}

AOAC International (1995). Official methods of analysis of AOAC International, vol. 2. Gaithersburg: AOAC International.

BASU, T. K.; DICKERSON, J. W. (2006) Vitamins in Human Health and Disease. CAB International.

BRAND-WILLIAMS, W.; CUVELIER, M. E.; BERSET, C. (1995) Use of a free radical method to evaluate antioxidant activity. Lebensmittel-Wissenschaft Technologie, London, v. 28, p. 25-30.

DUZZIONI, A. G.; LENTON, V. M.; SILVA, D. I. S.; BARROZO, M. A. S. (2013) Effect of drying kinetics on main bioactive compounds and antioxidante activity of acerola (Malpighia emarginata D.C.) residue. International Journal of Food science and Technology, v. 48, p. 1041-1047.

DORTA, E.; LOBO, M. G.; GONZÁLEZ, M., 2012. Using drying treatments to stabilize mango peel and seed: Effect on antioxidant activity. LWT- Food Science and Technology, 45, 261-268.

G1 MG, Nutricionista destaca benefícios do abacate para o emagrecimento. Acessado em: 08 de outubro de 2013. Disponível em: $\quad<\mathrm{http}: / / \mathrm{g} 1$. globo.com/minasgerais/noticia/2013/03/nutricionistadestaca-beneficios-do-abacate-para-oemagrecimento.html>.

MARQUES, L. G. (2008) Liofilização de frutas tropicais. Tese de doutorado. UFSCar, São Carlos.

MARQUES, L. G. e FREIRE, J. T. (2005) Analysis of freeze-drying of tropical fruits, Drying Technology, 24(4), p. 457463.

MINISTÉRIO DA SÚDE. (2002) Alimentos regionais brasileiros. Página 109. Secretaria de Políticas de Saúde, Coordenação-Geral da Política de Alimentação e Nutrição. Brasília: Ministério da Saúde, $1^{\mathrm{a}}$ ed.

OVERHULTS, D. G.; WHITE, G. M.; HAMILTON, H. E.; ROSS, I. J.; (1973) Drying soybeans with heate dair, Transactions of the ASAE, 16 (1), 112113.

PACHECO, C. R. F. Capítulo 1 - Conceitos básicos de secagem. Curso de especialização em papel e celulose, 2012. Escola Politécnica da Universidade de São Paulo.

PODSEDEK, A. (2007) Natural antioxidant and antioxidant capacity of Brassica vegetables: A review. LWT: Food Science and Technology, 40 (1), 1-11.

PUHL, J.; NITZKE. J. A. Secagem de vegetais. Secagem por infravermelho. ICTA, UFRGS. Acessado em: 08 de outubro de 2013. Disponível em: < http://www8.ufrgs.br/alimentus/objetos/ve g_desidratados/c_infravermelho.html >

SILVA, D. I. S.; NOGUEIRA, G. D. R.; DUZZIONI, A. G. (2013) Changes of antioxidante constituents in pineapple (Ananas comosus) residue during process. Industrial Crops and Products SD p. 557562. Elsevier Journal. Disponível em: elsevier.com/locate/indcrop.

SILVA, I. Q.; OLIVEIRA, B. C. F.; LOPES, A. S.; PENA, R. S. (2009) Obtenção de barra de cereais adicionada do resíduo industrial de maracujá. Faculdade de Engenharia de Alimentos, Instituto de tecnologia. UFPA, Belém, Pará. V. 20, n. 2, p. 321-329.

ZHISHEN, J., MENGCHENG, T., JIANMING, W. (1999) The determination of flavonoidcontents in mulberry and their scavenging effects on superoxide radicals. FoodChemistry 64, 555-559.

\section{AGRADECIMENTOS}

Ao CNPq, à FAPEMIG pelo apoio financeiro e à Universidade Federal de Uberlândia. 